\title{
EXTRAÇÃO SUPERCRÍTICA DE ESPILANTOL EM LEITO FIXO A PARTIR DE JAMBU (Acmella oleracea (J.) R.K. Jansen)
}

\author{
I. A. M. ZELIOLI ${ }^{1}$, V. S. de FREITAS ${ }^{2}$, R.A.F. RODRGUES ${ }^{3}$, F. A. CABRAL ${ }^{1}$ \\ ${ }^{1}$ Laboratório de Extração, Termodinâmica Aplicada e Equilíbrio, Faculdade de Engenharia de \\ Alimentos, Universidade Estadual de Campinas \\ 2 Programa de Pós-Graduação em Farmacologia, Anestesiologia e Terapêutica, Faculdade de \\ Odontologia de Piracicaba, Universidade Estadual de Campinas \\ ${ }^{3}$ Centro Pluridisciplinar de Pesquisas Químicas, Biológicas e Agrícolas, Divisão de Química \\ de Produtos Naturais, Universidade Estadual de Campinas \\ e-mail para contato: i.augustomz@gmail.com
}

\begin{abstract}
RESUMO - Nesse trabalho, procurou-se estudar a influência das condições operacionais (pressão e temperatura) em duas variáveis-alvo: rendimento total mássico e composição química do extrato. Para isso, testaram-se 3 níveis para cada variável e todas as suas combinações: temperaturas de $313,15 \mathrm{~K}, 323,15 \mathrm{~K}$ e $333,15 \mathrm{~K}$ e pressões de 19,61 MPa, 29,42 MPa e 39,23 MPa, para extração com $\mathrm{CO}_{2}$ supercrítico puro e depois, com uma mistura de $\mathrm{CO}_{2}+5 \% \mathrm{~m} / \mathrm{m}$ álcool etílico. Resultados mostraram que condições mais intensas favorecem maior rendimento em extrações com $\mathrm{CO}_{2}$ puro, além de que as maiores temperaturas favorecem a extração de espilantol (composto de interesse). Para os extratos feitos com o auxílio de co-solventes, resultados mostraram que tanto o rendimento como a quantidade de espilantol são inferiores à extração com solvente puro.
\end{abstract}

\section{INTRODUÇÃO}

Jambu (Acmella oleracea (L.) R.K. Jansen) é uma planta originária da América do Sul e muito comum em todo sudoeste asiático. No Brasil é muito utilizada na culinária (especialmente na região Norte) e também para tratamentos de dores de dente e de garganta, tuberculose, anemia e como estimulante de apetite (Di-Stasi et al., 2002; Lorenzi e Matos, 2008).

O espilantol encontra-se distribuído por toda a parte aérea do jambu em concentração variável, sendo que os métodos extrativos e os solventes utilizados influenciam na seletividade de sua extração. O emprego de dióxido de carbono supercrítico apresenta grande seletividade para o espilantol, resultando em extratos concentrados, contendo até $65 \%$ de espilantol quando extraídos das flores e de $47 \%$ quando extraídos dos caules (Dias et al., 2012).

Nesse contexto, a utilização de fluidos supercríticos na extração de compostos bioativos é uma alternativa promissora, pois apresenta vantagens em relação a técnicas convencionais, uma vez que não há resíduos tóxicos no extrato final e esta tecnologia permite a recuperação do solvente (Bernardo-Gil, 2013). 
O dióxido de carbono é o solvente usado com maior frequência, pois apresenta vantagens, como pressão crítica moderada e baixa temporada crítica $\left(73,8 \mathrm{~atm}, 31,1^{\circ} \mathrm{C}\right)$ permitindo a extração de compostos termo lábeis. O dióxido de carbono não é inflamável, é atóxico, existe em abundância e é praticamente inerte quimicamente, além de ter custo relativamente baixo (Cavalcanti, 2008; Bernardo-Gil, 2013).

A característica apolar do dióxido de carbono, o torna um solvente de caráter lipofílico, sendo esta sua maior desvantagem quando o objetivo são substâncias polares. Para contornar esse problema é possível a adição de pequenas quantias de co-solventes polares, tais como etanol e acetato de etila (Bernardo-Gil, 2013).

\section{MATERIAL E MÉTODOS}

\subsection{Material vegetal}

O material vegetal foi proveniente do cultivo e coleta no campo experimental do Centro Pluridisciplinar de Pesquisas Químicas Biológicas e Agrícolas (CPQBA - Unicamp). As partes aéreas do jambu foram secas em estufa com ventilação forçada por $48 \mathrm{~h}$ a $40^{\circ} \mathrm{C}$ até massa constante. A moagem foi realizada em moinho de facas com peneira de 48 mesh 0,297 $\mathrm{mm}$. Após secagem e moagem, o material foi mantido em embalagem de papel craft com revestimento de polipropileno com fechamento simples e armazenado em freezer $-80{ }^{\circ} \mathrm{C}$ até utilização.

\subsection{Caracterização da amostra}

A matéria-prima foi caracterizada em termos de distribuição granulométrica (peneiramento vibratório - método ASAE) e tamanho de partícula (cálculo do diâmetro geométrico médio), massa específica real (picnometria de gás hélio) e aparente (pesando-se uma massa compactada num volume conhecido), porosidade do leito fixo (calculada pela Equação 1) e determinação de teor de voláteis (gravimetria com secagem em estufa a $105^{\circ} \mathrm{C}$ e -100 $\mathrm{mmHg}_{\text {man. }}$ ) e de umidade (titulador automático Karl-Fischer).

$$
\varepsilon=1-\frac{\rho_{\text {aparente }}}{\rho_{\text {real }}}
$$

\subsection{Produção de extratos utilizando $\mathrm{CO}_{2}$ em fase supercrítica, com e sem a presença de co-solventes.}

As extrações em fase supercrítica foram realizadas no equipamento cujo PFD (sigla para Diagrama de Fluxo de Processo, em inglês) simplificado está ilustrado abaixo na Figura 1. Através de resultados preliminares, estabeleceram-se volumes fixos de $\mathrm{CO}_{2}$ e de álcool etílico para se realizar as extrações de único estágio. 
Figura 1. PFD simplificado do equipamento utilizado nas extrações supercríticas

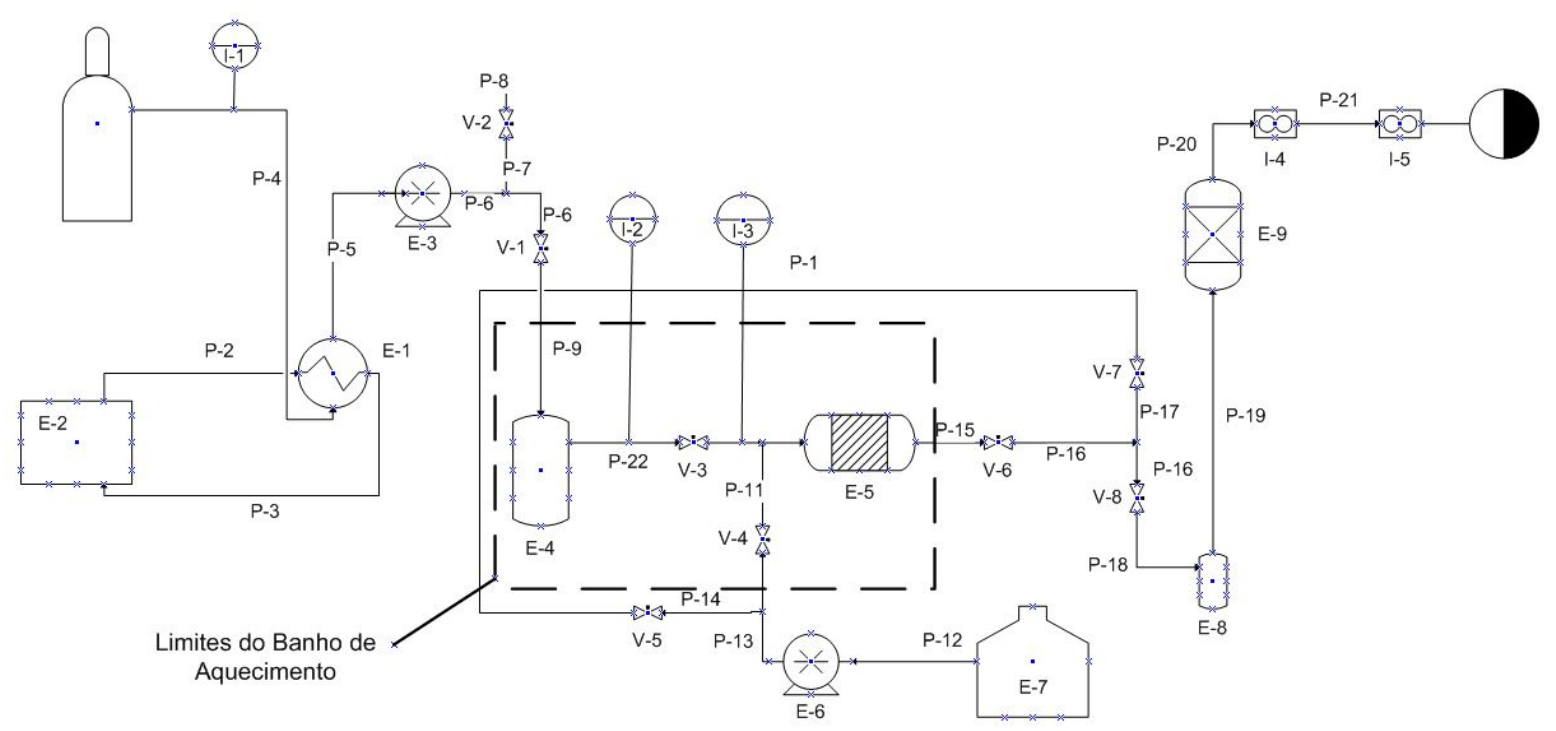

$\mathrm{O} \mathrm{CO}_{2}$ líquido provinha de um cilindro comercial padrão, sendo bombeado por uma bomba de pistão (E-3), passando por um trocador de calor (E-1) que o mantinha a $-10{ }^{\circ} \mathrm{C}$. Depois, a mesma bomba o transportava a um tanque pulmão (E-4), onde ele era pressurizado até o estado supercrítico. Ao abrir-se a válvula $\mathrm{V}-3, \mathrm{o} \mathrm{CO}_{2}$ supercrítico entrava no leito fixo (E-5) e o pressurizava até a pressão desejada. Observa-se que ambos estão dentro de um banho aquecido para se alcançar a temperatura de trabalho. Com o auxílio da regulagem da válvula V-6, a vazão era controlada. O extrato fora coletado no frasco E-8. As pressões do tanque pulmão e do leito fixo de amostra foram controladas pelos manômetros tipo Bourdon I-2 e I-3, respectivamente. A vazão volumétrica e o volume total consumido de $\mathrm{CO}_{2}$ foram lidos nos instrumentos I-4 e I-5, respectivamente. No caso da extração com presença de cosolvente, a válvula V-4 fora aberta e o solvente líquido (álcool etílico) fora bombeado por uma bomba de pistão (E-6) a partir do reservatório E-7, que basicamente consistira numa proveta.

No caso da extração com $\mathrm{CO}_{2}$ puro, o volume total foi de $180 \mathrm{~L}$, a uma taxa volumétrica de aproximadamente 1,5 $\mathrm{L} \mathrm{min}^{-1}$ (aprox. 2,5 $\mathrm{g} \mathrm{min}^{-1}$ ), o que totaliza 120 minutos de extração. No caso da extração com a presença de co-solvente, o volume total foi de $270 \mathrm{~L}$ de $\mathrm{CO}_{2}$, a uma taxa volumétrica de $1,5 \mathrm{~L} \mathrm{~min}^{-1}$, o que totaliza, aproximadamente 180 minutos de extração. O álcool etílico fora alimentado numa razão de $5 \%$ (em massa) do fluxo total. Essas decisões foram tomadas com base no fato de que, tanto a matéria prima como o composto de interesse (espilantol) são exaustivamente extraídos depois do consumo desses respectivos volumes aproximados de $\mathrm{CO}_{2}$. A extração utilizando-se o co-solvente fora realizada sequencialmente à extração feita com o $\mathrm{CO}_{2}$ puro, visando o maior esgotamento possível da matéria prima, em termos de composição de Espilantol. As extrações foram conduzidas para todas as combinações de três valores de pressão $\left(200,300,400 \mathrm{kgf} \mathrm{cm}^{-2}\right)$ e três de temperatura $\left(40,50\right.$ e $\left.60^{\circ} \mathrm{C}\right)$, totalizando nove experimentos. 


\subsection{Análise dos extratos obtidos}

O monitoramento analítico do espilantol foi realizado por cromatografia gasosa, empregando-se um cromatógrafo gasoso (CG Hewlett Packard 6890, série II, diretamente acoplado a um detector seletivo de massas Hewlett Packard $597570 \mathrm{eV}$ ) equipado com coluna de sílica fundida WCOT, HP5-MS, marca Agilent de dimensões $30 \mathrm{~m}$ x 0,25 mm DI, $0,25 \mu \mathrm{m}$ de espessura da fase estacionária. As condições de análise foram: temperatura de injeção: $220^{\circ} \mathrm{C}$, temperatura do detector: $250{ }^{\circ} \mathrm{C}$, programação de temperatura: $60-240{ }^{\circ} \mathrm{C}$, $\left(3{ }^{\circ} \mathrm{C} \mathrm{min}{ }^{-1}\right)$, com divisor de amostra na razão 1:40, gás de arraste $\mathrm{He} 0,7 \mathrm{bar}, 1 \mathrm{~mL} \mathrm{~min}{ }^{-1}$. Os extratos foram mantidos em freezer, a uma temperatura de $-20{ }^{\circ} \mathrm{C}$ até o momento da análise. A identificação do espilantol foi feita com o auxílio do banco de dados do National Institute of Standard Technology $\left(\right.$ NIST $\left.^{\circledR}\right)$ presente no software de análise MSD ChemStation da Agilent ${ }^{\circledR}$ com concordância mínima de $90 \%$.

As análises CG/EM foram conduzidas na Divisão de Química de Produtos Naturais, do Centro Pluridisciplinar de Pesquisas Químicas, Biológicas e Agrícolas (CPQBA-Unicamp).

\section{RESULTADOS E DISCUSSÕES}

A análise granulométrica resultou num diâmetro geométrico médio de partícula igual a $\mathrm{D}_{\mathrm{GM}}=(289,7 \pm 9,6) \mu \mathrm{m}$, a massa específica aparente $\rho_{\text {aparente }}=(0,326 \pm 0,011) \mathrm{g} \mathrm{cm}^{-3}$, massa específica real $\rho_{\text {real }}=(1,49 \pm 0,01) \mathrm{g} \mathrm{cm}^{-3}$ e pela Equação 1, porosidade do leito fixo $\varepsilon=$ $(0,7812 \pm 0,0075)$. $1 O$ teor mássico de voláteis totais resultou $T_{\text {voláteis }}=(10,02 \pm 0,56) \% \mathrm{~m} / \mathrm{m}$; e umidade $\mathrm{T}_{\text {umidade }}=(9,44 \pm 0,22) \% \mathrm{~m} / \mathrm{m}$.

As Figuras 2 e 3 abaixo mostram as superfícies tridimensionais obtidas pela regressão linear de um modelo quadrático completo dos dados de rendimento mássico total e também da área cromatográfica referente o pico de espilantol, obtidas nas análises de CG/EM. A Figura 2 é referente às extrações realizadas com $\mathrm{CO}_{2}$ supercrítico puro, enquanto que a Figura 3 é referente às extrações com a mistura de $\mathrm{CO}_{2}$ supercrítico e o co-solvente álcool etílico. A área cromatográfica foi escolhida para acompanhar a qualidade dos extratos, visto que um padrão analítico de espilantol tem um custo de mercado muito alto, não sendo possível, assim, realizar uma análise qualitativa/quantitativa mais apropriada como por exemplo, a técnica de HPLC (cromatografia líquida de alta eficiência).

Observando a Figura 2.A, pode-se notar que a condição mais branda $(\mathrm{T}=313,15 \mathrm{~K}$; P = $\left.1,96 \times 10^{7} \mathrm{~Pa}\right)$ não é adequada para a extração da matéria-prima, pois resultaram num rendimento mássico, significativamente inferior às outras condições. Pode-se ver também que o rendimento de extração é sensivelmente afetado pela modificação dos parâmetros operacionais, quando inicialmente em condições brandas. Isso pode ser notado principalmente observando e comparando a variação promovida quando a temperatura mudou de $313,15 \mathrm{~K}$ para $323,15 \mathrm{~K}$, e também quando a pressão sobre de $1,96 \times 10^{7} \mathrm{~Pa}$ para $2,94 \times 10^{7} \mathrm{~Pa}$. No entanto, quando as condições são novamente mudadas, desta vez em direção à as condições mais intensas, essa variação observada é mais sutil. Já a composição química de espilantol é aproximadamente constante nos extratos produzidos com $\mathrm{CO}_{2}$ supercrítico puro, com exceção dos valores obtidos em temperaturas mais altas $(\mathrm{T}=333,15 \mathrm{~K})$, como pode ser observado na Figura 2.B. 


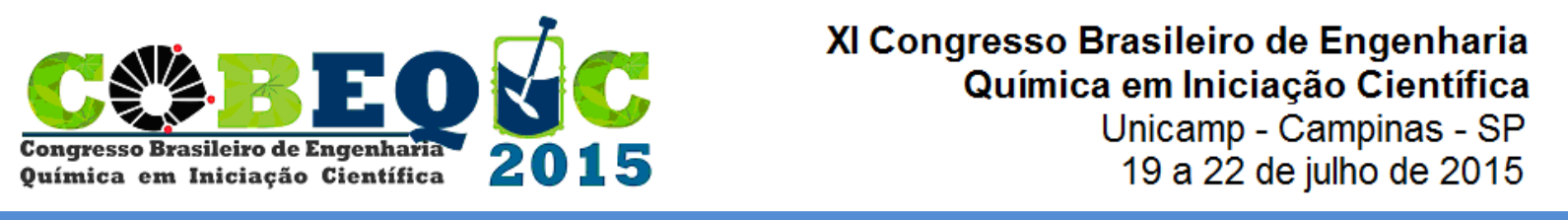

Figura 2. Superfícies de resposta obtidas para as extrações com $\mathrm{CO}_{2}$ supercrítico puro - A) rendimento mássico total; B) Área cromatográfica de Espilantol
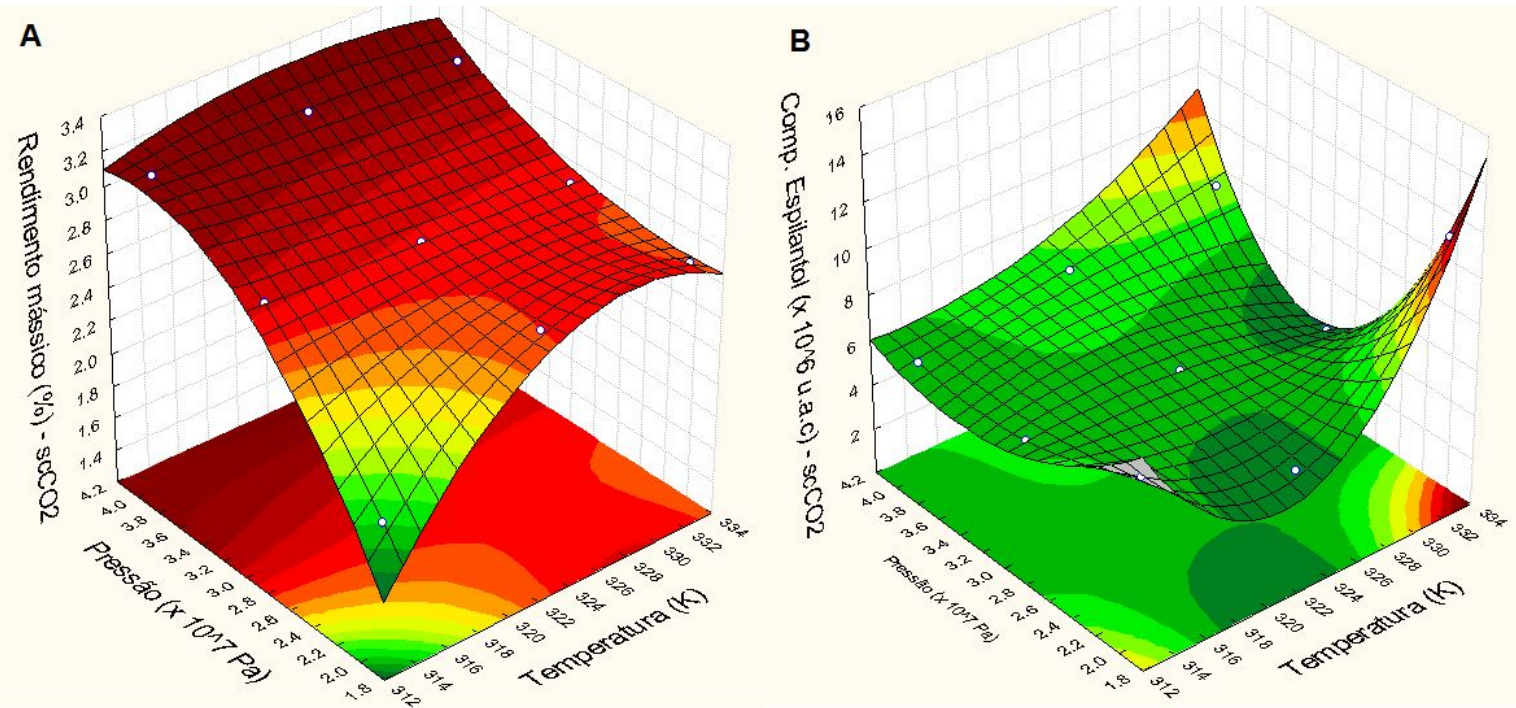

Figura 3. Superfícies de resposta obtidas para as extrações com $\mathrm{CO}_{2}$ supercrítico $+5 \%$ (massa) EtOH - A) rendimento mássico total; B) Área cromatográfica de Espilantol
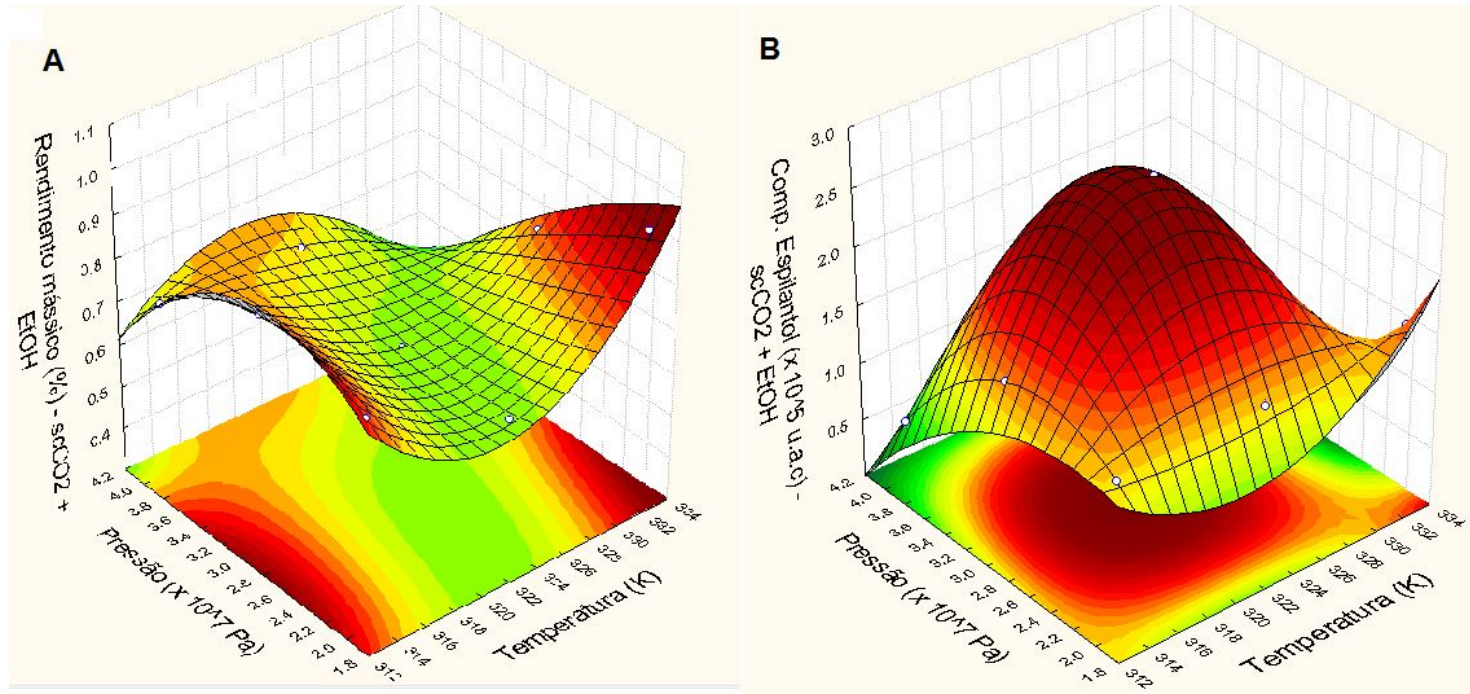

Observando agora a Figura 3.A, relativa ao rendimento mássico obtido nas extrações com $\mathrm{CO}_{2}$ supercrítico $+5 \%$ de álcool etílico como co-solvente, nota-se que a sensibilidade do método frente às modificações de processo é mais homogênea, ou seja, as variações são semelhantes por toda a superfície, ao contrário do que ocorre quando se usa apenas $\mathrm{CO}_{2}$ supercrítico. Isso possivelmente está associado ao fato de que a presença de uma fase líquida na mistura, pode modificar os comportamentos termodinâmicos. Pode-se observar existe um ponto de mínimo para a temperatura central e um máximo para a condição central de pressão (quando em temperatura baixa). No entanto, observa-se que os valores de rendimento mássico são significativamente menores dos observados na extração com $\mathrm{CO}_{2}$ supercrítico puro, fato esperado devido ao caráter sequencial da extração do co-solvente. 
Observando a Figura 3.B, nota-se um ponto de máximo central, o que imediatamente sugere a condição ótima de extração de Espilantol com auxílio de co-solvente. No entanto, observando as grandezas no eixos $\mathrm{Z}$ de cada gráfico respectivamente, nota-se que as áreas obtidas nos extratos com $\mathrm{CO}_{2}$ supercrítico puro são uma ordem de grandeza maior, o que sugere que o Espilantol tenha maior afinidade com solventes apolares.

\section{CONCLUSÕES}

Através dos resultados e argumentos apresentados nesse trabalho, conclui-se que a extração por tecnologia supercrítica é efetiva nesse caso, pois através dela, conseguiu-se produzir o extrato bruto da planta em questão, além de ser verificado que a substância de interesse (Espilantol) também é extraída nesse processo.

Mais especificamente, foi visto que o Espilantol apresentou solubilidade satisfatória em $\mathrm{CO}_{2}$ supercrítico puro, dispensando até mesmo a extração com co-solventes. Isso constitui em várias vantagens, visto que: 1. o tempo total de extração pode ser reduzido de cinco horas (duas horas de extração com $\mathrm{CO}_{2}$ puro + três horas com $\mathrm{CO}_{2}$ com co-solvente) para apenas duas horas de processamento com $\mathrm{CO}_{2}$ puro, o que, pensando numa escala industrial, reduziria custos de operação da planta; 2. o extrato contendo apenas $\mathrm{CO}_{2}$ como solvente é considerado ecologicamente melhor de que o que possui co-solvente, pois o $\mathrm{CO}_{2}$ pode ser simplesmente despressurizado e retornado à linha de produção, enquanto que o álcool etílico (em fase líquida) teria de ser eliminado por evaporação e depois devidamente descartado, implicando em maiores custos de capital fixo (instalação da estação de tratamento e dos evaporadores) e também de operação.

\section{REFERÊNCIAS BIBLIOGRÁFICAS}

BERNARDO-GIL, M.G.. Supercritical Extraction. In: TEIXEIRA, J.A.; VICENTE, A.A., editores. Engineering Aspects of Food Biotechnology. 1. ed. 2013. p. 215-250.

CAVALCANTI, V.M.S.. Extração de espilantol de Spilanthes acmela var oleraceae com dióxido de carbono supercrítico. Tese de doutorado apresentada à Faculdade de Engenharia Química como parte dos requisitos exigidos para a obtenção do título de Doutor em Engenharia Química. Campinas: Universidade Estadual de Campinas, Faculdade de Engenharia Química; 2008.

DIAS, A.M.A.; SANTOS, P.; SEABRA, I.J.; JUNIOR, R.N.C.; BRAGA, M.E.M.; SOUSA, H.C.. Spilanthol from Spilanthes acmella flowers, leaves and steams obtained by selective supercritical dioxide extraction. J. Supercrit. fluids. 2012; 61: 62-70.

DI-STASI, L.C.; HIRUMA-LIMA, C. A.; SANTOS, C. M.; GUIMARÃES, E. M.. Asterales medicinais. In: DI-STASI, L. C.; HIRUMA-LIMA, C. L.. Plantas medicinais na Amazônia e na mata atlântica. 2. Ed. São Paulo: Editora Unesp, 2002, p 472-3.

LORENZI, H., MATOS, F.J.A.. Plantas medicinais no Brasil: nativas e exóticas. 2. Ed. Nova Odessa: Instituto Plantarum de Estudos da Flora LTDA; 2008. p. 113. 